ANORECTAL DISEASE

\title{
Rectal sensorimotor dysfunction in patients with urge faecal incontinence: evidence from prolonged manometric studies
}

\author{
C L H Chan, P J Lunniss, D Wang, N S Williams, S M Scott
}

Gut 2005;54:1263-1272. doi: 10.1136/gut.2005.071613

See end of article for authors' affiliations

.....................

Correspondence to: Dr S M Scott, Centre for Academic Surgery, GI Physiology Unit, 3rd Floor Alexandra Wing, Royal London Hospital,

Whitechapel, London E1 1BB, UK; m.scott@ qmul.ac.uk

Revised version received 25 April 2005

Accepted for publication

28 April 2005

Published online first

24 May 2005
Background and aims: Although external anal sphincter dysfunction is the major cause of urge faecal incontinence, approximately $50 \%$ of such patients have evidence of rectal hypersensitivity and report exaggerated stool frequency and urgency. The contribution of rectosigmoid contractile activity to the pathophysiology of this condition is unclear, and thus the relations between symptoms, rectal sensation, and rectosigmoid motor function were investigated.

Methods: Fifty two consecutive patients with urge faecal incontinence, referred to a tertiary surgical centre, and 24 volunteers, underwent comprehensive anorectal physiological investigation, including prolonged rectosigmoid manometry. Patients were classified on the basis of balloon distension thresholds into those with rectal hypersensitivity $(n=27)$ and those with normal rectal sensation $(n=25)$. Automated quantitative analysis of overall rectosigmoid contractile activities and, specifically, high amplitude contractions and rectal motor complex activity was performed.

Results: External anal sphincter dysfunction was similar in both patient groups. Overall, phasic activity and high amplitude contraction frequency were greater, and rectal motor complex variables significantly altered, in those with rectal hypersensitivity. Symptoms, more prevalent in the rectal hypersensitivity group, were also more often associated with rectosigmoid contractile events. For individuals, reduced compliance and increased rectal motor complex frequency were only observed in patients with rectal hypersensitivity. Conclusions: We have identified a subset of patients with urge faecal incontinence-namely, those with rectal hypersensitivity-who demonstrated increased symptoms, enhanced perception, reduced compliance, and exaggerated rectosigmoid motor activity. Comprehensive assessment of rectosigmoid sensorimotor function, in addition to evaluation of anal function, should be considered in the investigation of patients with urge faecal incontinence.
M aintenance of bowel continence involves coordination between anorectal and colonic function, and psychobehavioural factors. Faecal incontinence is a major cause of social and psychological disability, reported in approximately $2 \%$ of the adult population, ${ }^{1}$ although this likely represents an underestimate as sufferers are often reluctant to volunteer such symptoms. ${ }^{23}$ Pathophysiology may be multifactorial. ${ }^{4}$ Urge faecal incontinence (UFI), where incontinent episodes occur against the patient's will, due to lack of voluntary control, is the most common presenting symptom. ${ }^{4}$ External anal sphincter (EAS) dysfunction, either secondary to compromised structural integrity, neurological injury, or a combination of both, is recognised as the major cause of UFI. ${ }^{5-7}$ Nevertheless, patients with an anatomically intact and normal functioning EAS also experience episodes of UFI, ${ }^{8}$ indicating that other pathophysiological mechanisms may contribute to symptoms. It is known that alterations in suprasphincteric mechanisms influence continence ${ }^{9}$ but their precise role in UFI remains undetermined. The reservoir function of the colorectum may be compromised, for example, by disturbance of sensorimotor function. ${ }^{10-12}$ Furthermore, as visceral sensory and motor mechanisms of the anorectum and colon are themselves inextricably linked, alterations in the motor component may effect change in sensory function, and vice versa. ${ }^{13}$ This interaction may be further modulated and modified by higher cortical centres. ${ }^{14}$

Evaluation of rectal sensory function in patients with UFI has demonstrated that up to $\sim 50 \%$ of patients have evidence of rectal hypersensitivity ( $\mathrm{RH})$ to simple volumetric balloon distension-that is, reduced sensory thresholds. ${ }^{5}{ }^{15}$ We have recently shown that in patients with UFI, RH is associated with increased bowel frequency, reduced ability to defer defecation, increased pad usage, and negative lifestyle effects. $^{5}$

Motor function of the colon and rectum is an integrated process involving myoelectrical and contractile activity, tone, compliance, wall tension, and stool transit. ${ }^{16}$ Although some information is available regarding the influence of alterations in certain motor components, such as compliance, ${ }^{10-12} 17$ tone, $^{18}$ and transit ${ }^{19}$ in UFI, little is known about the contribution of colorectal contractile activity to the pathophysiology of this condition. Numerous studies have used prolonged ambulatory manometry to investigate colonic contractile activity in normal subjects and patients with constipation, ${ }^{19-23}$ but few studies have used this technique to address possible colorectal dysmotility in faecal incontinence. ${ }^{19}{ }^{24}$ Colorectal motility comprises a number of distinct phasic contractile activities, both isolated and in recognisable patterns. ${ }^{25}$ Two components, high amplitude contractions and rectal motor complexes (RMC), have been shown to be functionally important in patients with faecal incontinence.

Abbreviations: ANOVA, analysis of variance; AUC, area under the curve; CS, control subjects; EAS, external anal sphincter; DDV, defecatory desire volume; HAC, high amplitude contraction; HADS, hospital anxiety and depression scale; HAPC, high amplitude propagated contraction; IAS, internal anal sphincter; IBS, irritable bowel syndrome; MTV, maximum tolerable volume; NS, normal rectal sensation; PNTML, pudendal nerve terminal motor latency; $\mathrm{RH}$, rectal hypersensitivity; RMC, rectal motor complex; SCID, structured and clinical interview for DSM-III-R; UFI, urge faecal incontinence 
In one study, a strong correlation between the urge to defecate (represented by depression of an event marker) and high amplitude propagated contractions (HAPC) was demonstrated in both healthy individuals and in the six patients with faecal incontinence. ${ }^{19}$ All episodes of urge incontinence were associated with propagation of HAPCs from the transverse colon to the rectum. ${ }^{19}$ HAPCs are the major motor correlates of mass intraluminal movement, ${ }^{26}$ and there is a clear association with both the urge to defecate $e^{22} 27$ and faecal expulsion. ${ }^{28}{ }^{29}$ In a separate study, Santoro et al showed RMC frequency to be increased in a proportion of patients with idiopathic faecal incontinence. ${ }^{24}$ The RMC is a subconscious intrinsic motor programme comprising regular cyclical bursts of phasic pressure waves. ${ }^{19} 230-32$ The function of the RMC remains unclear but is thought to represent localised segmental activity. ${ }^{31}$ It now appears that the RMC, although predominant in the rectosigmoid region, is indeed manifest throughout the colon, where it has been termed the colonic motor complex. ${ }^{20} 233132$ Like the small bowel migrating motor complex, which has been characterised to a much greater extent over the past three decades, ${ }^{1633}$ it has been proposed that the RMC may also be used as a marker of enteric neuromotor function, as its presence is independent of intact extrinsic innervation. ${ }^{34-36}$ Prolonged ambulatory manometry, which is now a well recognised clinical tool for the investigation of small intestinal dysmotility, ${ }^{37}$ as well as a research tool for the study of colorectal motility, ${ }^{25}$ has demonstrated that both qualitative and quantitative abnormalities of cyclical motor activity may be of pathological significance. ${ }^{21}{ }^{38-40}$

The primary aim of this study was to evaluate rectosigmoid motor activity over a prolonged period in a large cohort of patients with the specific symptom of UFI. The secondary aim was to investigate the relationships between rectal sensation and colorectal motor function, to test the hypothesis that the exaggerated symptoms observed in patients with rectal hypersensitivity are associated with differences in contractile activity.

\section{MATERIALS AND METHODS \\ Subjects}

Patients with urge faecal incontinence (UFI)

The study population consisted of 52 patients with UFI ( 38 females; median age 45.5 years (range 18-72)) referred consecutively to a tertiary surgical coloproctology centre. All patients had a detailed clinical history taken and underwent investigations to exclude organic gastrointestinal pathology. From their histories, details regarding symptom onset, bowel frequency, and frequency of incontinence episodes were recorded. All patients also underwent a structured clinical interview (SCID) for DSM-III-R (Diagnostic and Statistical Manual of Mental Disorders) to screen for psychopathology ${ }^{41}$ and completed validated screening questionnaires: the bowel disease questionnaire ${ }^{42}$ and the hospital anxiety and depression scale (HADS). ${ }^{43}$ These questionnaires were used to identify the presence of the irritable bowel syndrome (IBS), as defined by the Rome II criteria, ${ }^{44}$ and anxiety or depressive disorders. A score of up to 7 in either the anxiety or depression scale of the HADS is regarded as normal, 8-10 as mild anxiety or depression, 11-14 as moderate anxiety or depression, and $15-21$ as severe anxiety or depression. ${ }^{43}$

\section{Normal healthy volunteers}

Twenty four healthy volunteers (16 females; median age 29 years (range 18-55)), recruited by advertisement, were used as control subjects (CS). There was no evidence in any of the subjects of organic or functional gastrointestinal disorder as assessed by detailed clinical history, bowel symptom questionnaire, ${ }^{42}$ or physical examination. Anxiety and depressive disorders were excluded through the same structured clinical interview (SCID), ${ }^{41}$ and completion of the HADS $^{43}$

Approval for these studies was obtained from the East London and City Health Authority Research Ethics Committee (P01/84), with written informed consent obtained from all patients.

\section{Anorectal physiological investigation \\ Standard techniques}

All subjects underwent detailed standard anorectal physiological investigations, which included station pull through manometry of the anal canal, evaluation of rectal sensory thresholds using a volumetric based balloon distension technique, assessment of pudendal nerve terminal motor latencies, and endoanal ultrasonography.

Manometry was performed using a single channel side hole catheter linked to an Arndorfer-type pneumohydraulic water perfusion system; a pull back technique allowed assessment of functional anal canal length, maximum resting tone, and maximum voluntary squeeze pressures. ${ }^{45}$ Anal resting tone and squeeze pressures were considered abnormal if they were below $50 \mathrm{~cm} \mathrm{H}_{2} \mathrm{O}$, which are the lower limits of normal for our unit, as determined from investigation of the 24 control subjects involved in this study plus 32 further controls ( 56 in total). Rectal sensation was tested by inflating a latex balloon with air at $1 \mathrm{ml} / \mathrm{s}$ and determining the threshold volumes for first constant sensation, defecatory desire volume (DDV), and maximum tolerable volume (MTV). ${ }^{46}$ Patients were considered to have RH if MTV was $<100 \mathrm{ml}$ in females or $<80 \mathrm{ml}$ in males (determined in 56 healthy control subjects). Pudendal nerve terminal motor latencies (PNTML) were recorded with the St Mark's pudendal stimulating electrode (Dantec Electronics Ltd, Bristol, UK). ${ }^{47}$ PNTML are known to increase with age ${ }^{48}$; patients were considered to have a pudendal neuropathy (either unilateral or bilateral) if PNTMLs exceeded $2.3 \mathrm{~ms}$ in those $<40$ years of age, and exceeded $2.5 \mathrm{~ms}$ in those $\geqslant 40$ years of age. These values represent the upper limit of normal for our unit. Endoanal ultrasound ( $10 \mathrm{MHz}$ transducer; B\&K Medical, UK) was used to assess sphincter integrity. ${ }^{49}$

\section{Advanced techniques \\ Barostat study}

An electronic barostat (Synectics Visceral Stimulator; Synectics Medical, Stockholm, Sweden) was used to measure rectal compliance. Employing a stepwise isobaric distension protocol, ${ }^{50}$ analogue signals from the barostat were amplified and digitised by an interface converter (PC Polygraph HR; Synectics Medical, Enfield, Middlesex, UK) and transmitted to a PC at a sampling rate of $32 \mathrm{~Hz}$ for online display and subsequent storage to hard disk. A dedicated software program (Polygram for Windows version 1.1; Synectics Medical, UK) was used for online monitoring and analysis purposes.

With no sedation or bowel preparation, and with subjects lying in the left lateral position, sigmoidoscopy was performed to ensure an empty rectum (all cases). An "infinitely" compliant (that is, within the pressure-volume range studied) barostat bag (maximum capacity $500 \mathrm{ml}$; Medtronic Functional Diagnostics Zinectics Inc, Utah, USA) mounted on a manometric catheter (internal diameter $3 \mathrm{~mm}$ ) and fixed at both ends, was then inserted into the rectum, after ensuring that there was no leakage from the system. The catheter was connected to the barostat with an inflation and deflation port. Maximal airflow was $38 \mathrm{ml} / \mathrm{s}$. In an attempt to stabilise basal tone, reduce variability in sensory thresholds and compliance (that is, to improve 
reproducibility), and familiarise subjects with the procedure, a conditioning distension protocol was performed..$^{51}$ When inflated, the bag became spherical with a length of $8 \mathrm{~cm}$.

After allowing the system to equilibrate for a further five minutes, bag pressure was then increased from 0 to $32 \mathrm{~mm} \mathrm{Hg}$ (or maximum toleration) in $2 \mathrm{~mm} \mathrm{Hg}$ steps and continued for one minute, followed by a one minute rest. At each pressure step, the mean bag volume over the last 30 second segment was recorded..$^{51}$ Static rectal wall compliance $(\mathrm{ml} / \mathrm{mm} \mathrm{Hg})$ was calculated as the slope $(\delta \mathrm{V} / \delta \mathrm{P})$ of the compliance curve between the pressure thresholds of first constant and maximum tolerable distension volumes. ${ }^{50}$ From 56 control subjects, the normal range for rectal compliance was taken as $8.6-19.1 \mathrm{ml} / \mathrm{mm} \mathrm{Hg}$.

\section{Prolonged rectosigmoid manometry \\ Recording system}

Prolonged manometry was carried out using a portable ambulatory recording system (Flexilog 3000; Oakfield Instruments Ltd, Eynsham, Oxon, UK), connected to a Konigsberg solid state manometry catheter (Konigsberg Instruments Inc, Pasadena, California, USA) ${ }^{8}$ incorporating six transducers, spaced $5 \mathrm{~cm}$ apart, and calibrated over a range of $0-200 \mathrm{~mm} \mathrm{Hg}$.

No prior bowel preparation or sedation was used. All medications known to affect bowel function, such as loperamide, were discontinued for at least 48 hours prior to the study. A strong suture was tied to the tip of the catheter and grasped by biopsy forceps passed down the channel of a flexible sigmoidoscope. With the patient in the left lateral position, the catheter was then introduced into the rectosigmoid in tandem with the sigmoidoscope, using minimal air insufflation. Under direct vision, the catheter was sited with the most proximal transducer $(+25 \mathrm{~cm})$ located in the sigmoid and the most distal transducer $(0 \mathrm{~cm})$ in the anal canal. The sigmoidoscope was then carefully withdrawn, ensuring the catheter's position was maintained. This procedure took no longer than five minutes in all cases. The catheter was then secured in place with tape (Mefix; SCA Molynlycke, UK) and connected to the portable recording system, which was secured in a shoulder harness. Recorded data were stored on a memory card and downloaded to a personal computer for subsequent display and analysis.

\section{Study protocol}

In general, prolonged manometric studies were commenced between 13:00 and 15:00. Recordings were started immediately once all the equipment was in place and the patient ambulant. If the catheter was not expelled during defecation, recordings were continued for approximately 20 hours until the next morning when the catheter was removed electively using gentle traction. Fluoroscopic examination in a subgroup of patients $(n=4)$ confirmed that the position of the catheter was maintained overnight. Subjects were allowed to go home and were encouraged to engage in their normal daily activities. Fluid intake was allowed ad libitum. Neither meal composition nor subject activities was standardised to avoid inducing further stress which may in turn influence colonic motility. ${ }^{52}$ Instructions were given to retire to bed at 23:00. Subjects were informed to depress an event marker on the recorder when the urge to defecate was perceived. A diary of events recording bedtime, time of wakening, and meal and drink times were carefully recorded.

\section{Data analysis}

Overall activity

Automated (quantitative) analysis of overall rectosigmoid contractile activity was initially performed using a validated commercially available computer software program (Flexisoft
III, Data Display \& Analysis v 2.6.0; Oakfield Instruments Ltd., Oxon, UK). A pressure wave exceeding a threshold of $5 \mathrm{~mm} \mathrm{Hg}$, without a simultaneous pressure event occurring in the other four rectal/sigmoid recording channels, was assessed by the computer algorithm as being the consequence of a sigmoid/rectal contraction. These pressure events were predominantly monophasic elevations that had a discernible onset, peak, and offset, and that did not have the features of strain artefact.

For the purposes of analysis, each recording was divided into nocturnal and diurnal periods. The nocturnal period was defined by diary entries. Given the volume of the data recorded, three of the six catheter recording sites were chosen for analysis, at $+25 \mathrm{~cm},+15 \mathrm{~cm}$, and $+10 \mathrm{~cm}$ above the mid anal canal, to represent the sigmoid colon, rectosigmoid, and mid-rectum, respectively. As it is very difficult to maintain a point sensor accurately within the high pressure zone of the anal canal, ${ }^{19}$ marked fluctuations in anal pressure were seen to occur secondary to movement artefact. Consequently, a detailed quantitative analysis of anal motility (that is, from the most distal sensor) was not performed. For rectosigmoid activity, recorded measurements included:

(a) per cent of recording time comprising phasic contractile activity;

(b) contraction frequency;

(c) median contraction amplitude;

(d) maximum contraction amplitude; and

(e) area under the pressure curve.

\section{Specific contractile events}

The automated analysis of two specific contractile events, namely high amplitude contractions (HAC) and RMCs, was performed using a separate computer program that has previously been developed and validated "in house" for the computerised assessment of small bowel motility..$^{43}$ Analysis was performed from recording sites at $+25 \mathrm{~cm}$, $+15 \mathrm{~cm}$, and $+10 \mathrm{~cm}$. HACs were defined as individual phasic events which exceeded $50 \mathrm{~mm} \mathrm{Hg}^{34} 5254$ in amplitude. For each subject, the frequency of HACs during the recording period was determined. RMCs were defined as bursts of phasic pressure waves lasting $\geqslant 3$ minutes, with a contraction frequency of $\geqslant 2 / \min ^{23}{ }^{30-32}$ Each RMC was identified visually and demarcated manually as a "region of interest" from which RMC frequency (No/h) could be calculated. Automated analysis of contractions within each region of interest allowed calculation of five further separate variables: (i) periodicity, (ii) complex duration, (iii) contraction frequency, (iv) median contraction amplitude, and (v) area under the pressure curve.

\section{Symptoms}

The temporal relationship between the symptom of urgency, as defined by an "event" as recorded by the patient, and rectal/sigmoid motor events (HAC, RMC) was assessed visually. A temporal association was defined as occurring within 60 seconds (30 seconds either side) of depression of the event marker. Qualitative analysis was performed on all recordings by two investigators.

\section{Statistical analysis}

Two test groups were defined, based on the results of rectal sensory function testing: those with $\mathrm{RH}$ and those with normal sensation (NS). Of the 52 patients with UFI, 27 were found to have RH (22 females; median age 49 years (range 28-72)) and 25 had NS ( 16 females; median age 45.5 years (range 18-63)). 
Clinical, anorectal physiology, and barostat data Data are expressed as mean (SD) or median (range), depending on whether the recorded values assumed a Gaussian distribution. Results were compared between test groups and CS using one way analysis of variance (ANOVA) or the Kruskal-Wallis test for parametric or non-parametric data, where appropriate, using a commercially available statistical software package (Prism 3.0; GraphPad Software Inc., San Diego, California, USA). For each test, the number of individual subjects in whom recorded values fell outside the respective normal ranges was recorded. Whether contingencies differed between groups was tested using the $\chi^{2}$ or Fisher's exact test.

\section{Prolonged rectosigmoid manometry Overall contractile activity and HAC}

Data were expressed and results compared in the same way as for clinical, physiological, and barostat data.

\section{RMC variables}

Due to the cyclical nature of rectosigmoid motility, prolonged manometric studies produce repeated measures of each RMC variable (periodicity, duration, frequency, amplitude, and area under the curve (AUC)) for each individual subject studied. As a result, conventional statistical methods, which assume a simple independent and non-repeated data structure, should not be employed for such data analysis. Failure to take into account the hierarchical structure in the analysis will give misleading results..$^{55}$ To account for the nonindependence between such repeated measures, we used a mixed effects model for the data analysis, which is a generalisation of an ANOVA model designed to be especially powerful under these circumstances. ${ }^{56}$ Through application of the mixed effects model, an estimate for the effect of RH or NS patients over CS, its $95 \%$ confidence interval (CI), and its statistical significance were calculated. ${ }^{57}$ In order to maintain normal distribution of residuals (random errors) in the mixed effects model, data for each RMC variable were first transformed logarithmically to derive a single summary statistic for each individual, and the expected effect and its 95\% confidence interval from the model were then antilog transformed. Using this methodology, the estimated effect for a variable should be interpreted as relative change. To assess whether the effect for a variable depends on time (day and night), an interaction between group (RH, NS, CS) and time was fitted for each variable. Effect was presented separately according to time if the interaction was significant at the 5\% level. The mixed effects model was estimated through an SAS PROC MIXED procedure ${ }^{56}$ in SAS version 8.2 (SAS Institute, Cary, North Carolina, USA).

RMC frequency, during both nocturnal and diurnal periods, was compared between groups using one way ANOVA. From previous studies, ${ }^{23} 2430-3239$ the upper limit of normal for RMC frequency is reported as $2.0 / \mathrm{h}$ during the day and $3.3 / \mathrm{h}$ at night. The proportions of individuals in the test groups, with an RMC frequency exceeding the upper limit of normal, were recorded, and contingencies were compared using Fisher's exact test. The other five RMC variables were evaluated using repeated measures ANOVA by means of the mixed effects model.

\section{Correlations with other variables}

Direct examinations of the presence of any correlations between prolonged manometric measurement variables and anorectal physiology and clinical history were made. Linear correlation or regression was used to compare the covariation of two numerical variables. When correlation was applied, parametric (Pearson correlation) or non-parametric (Spearman correlation) methods were used as appropriate.
For all tests, a p value of less than 0.05 (two sided test) was considered to be statistically significant. As this was an exploratory study, no adjustment for multiple comparisons were made in the analysis. Caution must therefore be exercised when a p value is near to 0.05 , whereas when a $\mathrm{p}$ value is small, the observed difference is unlikely to be spurious.

\section{RESULTS}

\section{Clinical history}

Duration of symptoms was equivalent between those patients with RH and those with NS (48 months (range 9-432) $v$ 48 months (range 2-216)). In female patients, parity was equivalent between study groups (RH: median 2 (range 010); NS: median 2 (range 1-5)).

Reported bowel frequency (fig 1) was significantly higher in patients with $\mathrm{RH}$ (median 4.75 bowel actions/24 hours (range 1-8)) than those with NS (median 2 bowel actions/ 24 hours (range $0.15-9$ ); $\mathrm{p}=0.002$ ).

\section{Psychological and psychiatric assessment}

The structured clinical interview (SCID) for DSM-III- ${ }^{41}$ did not reveal the presence of any psychological or psychiatric illnesses in any of the patients or healthy volunteers. The bowel symptom questionnaire and application of the Rome II criteria did not identify any patient or healthy volunteer as having IBS.

The anxiety scale was similar for the RH and NS groups (RH median 7 (range 0-17) v NS 7 (1-14)). Individually, 37\% of patients with RH (10/27) were classified as suffering from anxiety compared with $40 \%$ in the NS group (10/25). There were also no significant differences in the depression scale between the RH and NS groups (RH median 4 (range 0-9) $v$ NS $4(0-13))$. Again, the proportion of individuals with depression did not differ between the RH and NS groups ( $11 \% \vee 20 \%)$. There was no evidence of increased anxiety (median 0 (range 0-4)) or depression (median 1 (range 0-3)) in any of the control subjects.

\section{Anorectal physiology}

\section{Anal sphincter function}

Twenty one patients with RH (78\%; data from one subject missing) and 15 patients with NS (60\%; data from one subject missing) had reduced anal squeeze pressures $\left(<50 \mathrm{~cm} \mathrm{H}_{2} \mathrm{O}\right)$. Only four patients with $\mathrm{RH}(15 \%)$ and four with NS $(16 \%)$ had both a structurally intact EAS on

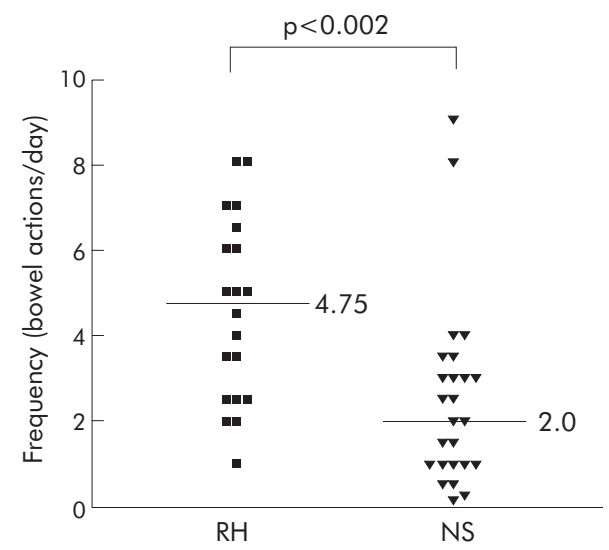

Figure 1 Reported bowel frequency in the rectal hypersensitivity (RH) and normal rectal sensation (NS) groups. A significantly higher median stool frequency was reported in the RH compared with the NS group $(4.75 \vee 2.0)$. 


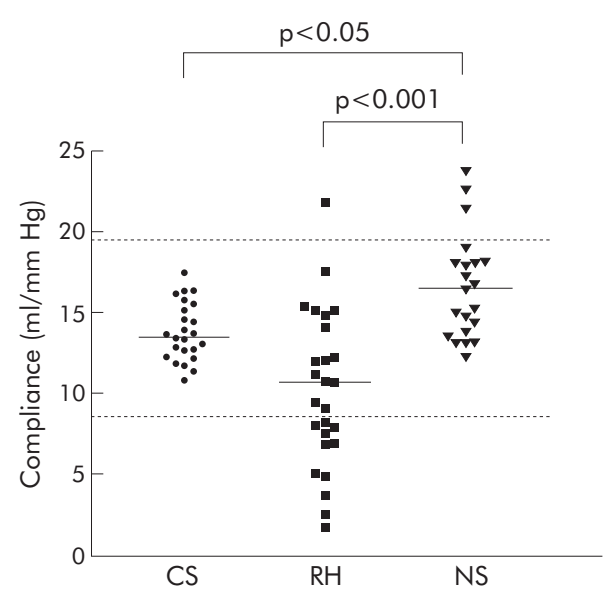

Figure 2 Rectal compliance in control subjects (CS) and in those with rectal hypersensitivity (RH) and normal rectal sensation (NS).

Compliance of 12 patients with RH and three with NS lay outside the normal range (broken line: $8.6-19.1 \mathrm{ml} / \mathrm{mm} \mathrm{Hg}$ (mean (2SD)). Rectal compliance was significantly lower in patients with RH compared with NS $(p<0.001)$.

ultrasound and normal PNTMLs. Pathophysiology of EAS dysfunction was similar between the two groups.

Although there was a significantly greater incidence of internal anal sphincter (IAS) defects identified on endoanal ultrasound in those with $\mathrm{RH}(46 \%)$ than in patients with NS $(17 \% ; p=0.04)$, IAS function, as defined manometrically, was similar between those with RH and NS. Anal resting tone was reduced $\left(<50 \mathrm{~cm} \mathrm{H}_{2} \mathrm{O}\right)$ in $58 \%$ of patients with $\mathrm{RH}$ and $48 \%$ of patients with NS.

\section{Rectal sensory function and compliance}

By definition, rectal sensory thresholds were significantly lower in the group with RH (mean DDV 48 (SEM 3) ml; MTV 74 (4) $\mathrm{ml}$ ) than those with NS (DDV 119 (12) ml, p<0.00l; MTV 193 (12) ml; p<0.001) and control subjects (DDV 107 (7) $\mathrm{ml}, \mathrm{p}<0.001$; MTV 176 (12) ml, p<0.001). There were no differences in rectal sensitivities between patients with NS and CS.

Rectal compliance (fig 2) was reduced (that is, the rectum was "stiffer") in patients with RH compared with those with NS (mean 10.8 (1.1) ml $/ \mathrm{mm} \mathrm{Hg} v 17.8$ (1.4) ml/mm Hg; $\mathrm{p}=0.001)$. Patients with NS had elevated rectal compliance in comparison with control subjects (compliance 13.9 (0.4) $\mathrm{ml} / \mathrm{mm} \mathrm{Hg} ; \mathrm{p}<0.05$ ), with three patients having values above the normal range. Although grouped data for rectal compliance were similar between patients with $\mathrm{RH}$ and healthy volunteers, 11/27 RH patients $(41 \%)$ had a compliance value $<8.6 \mathrm{ml} / \mathrm{mm} \mathrm{Hg}$, which is the lower limit of normality (mean $-2 \mathrm{SD}$ ), as determined previously in our unit. No patient with NS had rectal compliance below that of the normal range $(p=0.0003 v$ patients with $\mathrm{RH})$.

\section{Prolonged rectosigmoid manometry}

All subjects tolerated catheter insertion, and no complications were noted during insertion, monitoring, or withdrawal. Although sex matched, control subjects were significantly younger than both RH $(p=0.001)$ and NS $(\mathrm{p}=0.004)$ patients.

\section{Recording time}

Overall recording time in the 76 subjects was 1243 hours (by study group: CS 445 hours; RH 429 hours; NS 369 hours). Mean recording time was $18.6(0.5)$ hours in control subjects, which was equivalent to that in patients with $\mathrm{RH}$ (15.9 (1.2) hours) but greater than that in patients with NS (15.1 $(0.9)$ hours; $p<0.05)$. Six studies in patients with $\mathrm{RH}$ $(\mathrm{p}<0.03 v$ control subjects $)$ and five studies in patients with NS ( $p=0.05 v$ control subjects) were terminated prematurely because of catheter expulsion during defecation. In none of these was nocturnal activity recorded. In healthy volunteers, all recording catheters were removed electively. The start time of recordings was similar between groups ( RH 13:30 \pm 30 minutes; NS 14:30 \pm 20 minutes; CS $14: 30 \pm 20$ minutes).

\section{Symptoms of urgency}

Patients with RH were more frequently symptomatic than either patients with NS or controls. The median number of times per hour the event (symptom) marker was depressed in patients with RH was 0.5 (range $0-4$ ), which was significantly greater that in patients with NS $(0.24$ (range $0-1.3)$; $\mathrm{p}<0.01$ ) and controls (0.05 (range 0-0.3); $\mathrm{p}<0.001$ ).

\section{Temporal association between event marker and rectal contractile activity}

In patients with $\mathrm{RH}$, the event marker was depressed a total of 326 times (median 11 (range 0-57)). Urge to defecate was associated with a HAC in 128 cases (39\%), which was significantly higher than in the NS group in whom depression of the event marker correlated with a HAC in $21 \%$ of instances $(25 / 117 ; p=0.004)$. In controls, the event marked was depressed in association with a HAC in $28 \%$ of instances (9/32), similar to those with NS. Urge to defecate was associated with RMC activity in 21\% (67/326), 19\% (22/ $117)$, and $16 \%(5 / 32)$ in the RH, NS, and CS groups, respectively, with no differences between the groups. Overall, in patients with $\mathrm{RH}$, there was an association between the symptom of urgency and rectosigmoid motor events in $72 \%$ of cases compared with $45 \%$ and $50 \%$ of the NS and CS groups, respectively $(\mathrm{p}<0.0001$ and $\mathrm{p}<0.03$, respectively).

Table 1 Parameters of overall contractile activity at the recording site: $+15 \mathrm{~cm}$ above the mid anal canal (representing the rectosigmoid) in control subjects (CS) and in those with rectal hypersensitivity (RH) and normal rectal sensation (NS)

\begin{tabular}{lcccc}
\hline Parameter & \multicolumn{2}{c}{ CS } & RH & NS \\
\hline Contractile activity (\% of recording time) & +15 & $22.6(1.3)$ & $22.8(1.4)$ & $20.2(1.2)$ \\
Contraction frequency (No/min) & +15 & $1.6(0.1)$ & $1.5(0.1)$ & $1.4(0.09)$ \\
Median amplitude (mm Hg) & +15 & $9.6(0.3)^{*}$ & $9.8(0.4)^{*}$ & $8.4(0.3)$ \\
Maximum amplitude (mm Hg) & +15 & $124(9)^{* *}$ & $127(8)^{* *}$ & $87(8)$ \\
AUC (mm Hg/min) & +15 & $84(6)^{*}$ & $90(7)^{* *}$ & $61(5)$ \\
\hline
\end{tabular}

${ }^{*} \mathrm{p}<0.05,{ }^{* *} \mathrm{p}<0.01$ versus NS.

For activity at $+25 \mathrm{~cm}$ (sigmoid) and $+10 \mathrm{~cm}$ (rectum), please refer to the Gut website at http://www.gutjnl.com/ supplemental. 
Table 2 Frequency of high amplitude contractions ( $>50 \mathrm{~mm} \mathrm{Hg} / \mathrm{h}$ ) during the day and night in control subjects (CS) and in those with rectal hypersensitivity (RH) and normal rectal sensation (NS), at the recording site $+15 \mathrm{~cm}$ above the mid anal canal

\begin{tabular}{lllll}
\hline Site & & CS & RH† & NS $\ddagger$ \\
\hline Diurnal & +15 & $1.1(0.2)^{*}$ & $2.3(0.6)$ & $1.1(0.8)^{* *}$ \\
Nocturnal & +15 & $0.3(0.1)^{*}$ & $1.3(0.3)$ & $1.6(0.9)$ \\
\hline
\end{tabular}

${ }^{*} \mathrm{p}<0.05,{ }^{* *} \mathrm{p}<0.01$ versus $\mathrm{RH}$

†No nocturnal data, $n=6$; ¥no nocturnal data, $n=5$.

For high amplitude contraction activity at other levels, please refer to the

Gut website at http://www.gutjil.com/supplemental.

Overall contractile activity (table 1)

The percentage recording time taken up by contractile activity and overall contraction frequency were similar between the groups at all three levels studied. However, median contraction amplitude was significantly greater in patients with RH and CS compared with NS patients at $+15 \mathrm{~cm}(\mathrm{p}<0.05$ and $\mathrm{p}<0.05$, respectively). Maximum contraction amplitude was also significantly greater in patients with $\mathrm{RH}$ and CS compared with NS patients at both $+25 \mathrm{~cm}$ and $+15 \mathrm{~cm}$ $(+25 \mathrm{~cm}: \mathrm{p}<0.01$ and $\mathrm{p}<0.05$, respectively; $+15 \mathrm{~cm}: \mathrm{p}<0.01$ and $\mathrm{p}<0.01$, respectively). Consequently, the AUC was greater in $\mathrm{RH}$ patients than those with $\mathrm{NS}$ at all levels $(+25 \mathrm{~cm}: \mathrm{p}<0.05 ;+15 \mathrm{~cm}: \mathrm{p}<0.01 ;+10 \mathrm{~cm}: \mathrm{p}<0.01)$. AUC in controls was also greater than in patients with NS at $+15 \mathrm{~cm}$ $(\mathrm{p}<0.05)$. AUC was similar between CS and patients with $\mathrm{RH}$.

HACs

Daytime frequency of HAC (table 2) was increased in patients with RH compared with patients with NS at all levels studied $(p<0.01)$. In addition, nocturnal frequency of HAC was higher in RH patients than in NS patients at both $+25 \mathrm{~cm}$ $(\mathrm{p}<0.05)$ and $+10 \mathrm{~cm}(\mathrm{p}<0.05)$. In comparison with control subjects, the frequency of contractions $>50 \mathrm{~mm} \mathrm{Hg}$ was higher in $\mathrm{RH}$ patients at both $+25 \mathrm{~cm}$ and $+15 \mathrm{~cm}$ during the day $(\mathrm{p}<0.05$, respectively) and at $+15 \mathrm{~cm}$ at night $(\mathrm{p}<0.05)$.

\section{Rectal motor complex (RMC) activity}

RMC frequency (fig 3)

For grouped data, RMC frequency in RH patients was significantly increased both during the daytime and at night compared with control subjects at all levels of the study segment (diurnal: $+25 \mathrm{~cm}, \mathrm{p}<0.001$; $+15 \mathrm{~cm}, \mathrm{p}<0.05$; $+10 \mathrm{~cm}, \mathrm{p}<0.01$; nocturnal: $\mathrm{p}<0.001$ at all levels). Likewise, RMC frequency was significantly higher in RH patients than NS patients at all levels during the night $(p<0.001)$ and at $+25 \mathrm{~cm}(\mathrm{p}<0.01)$ and $+10 \mathrm{~cm}(\mathrm{p}<0.05)$ during the day. The

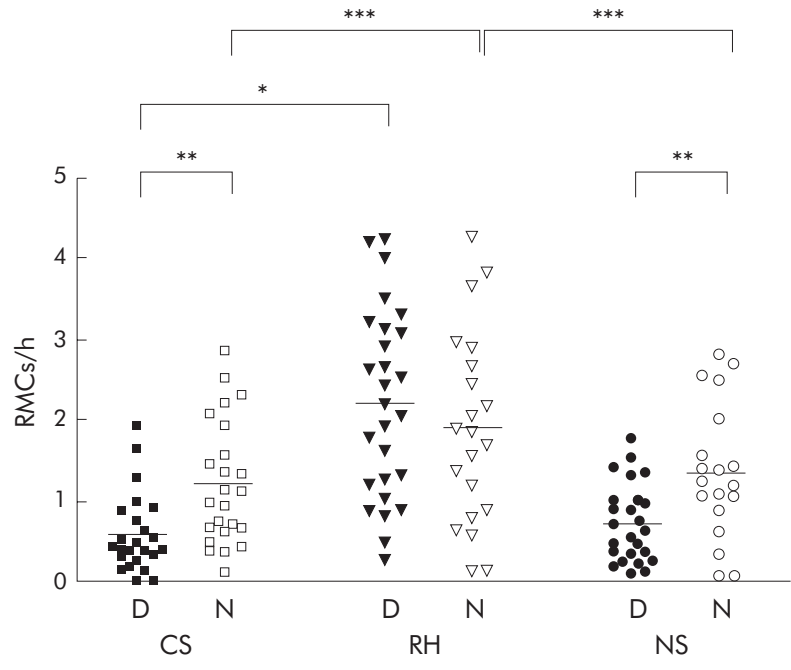

Figure 3 Diurnal (D) and nocturnal (N) rectal motor complex (RMC) frequency in control subjects (CS) and in those with rectal hypersensitivity (RH) and normal rectal sensation (NS), recorded at $+15 \mathrm{~cm}$ above the mid anal canal. ${ }^{*} p<0.05 ;{ }^{* *} p<0.01 ;{ }^{* * *} p<0.001$. For data at other recording levels, please refer to the Gut website at http://www. gutjinl.com/supplemental.

frequency of RMCs was similar between NS patients and control subjects both in the diurnal and nocturnal periods. Within groups, RMC frequency was greater at night in both control subjects and patients with NS at $+15 \mathrm{~cm}$ and $+10 \mathrm{~cm}$ $(+15 \mathrm{~cm}, \mathrm{p}<0.01$ and $\mathrm{p}<0.01$, respectively; $+10 \mathrm{~cm}, \mathrm{p}<0.001$ and $\mathrm{p}<0.05$, respectively). In patients with $\mathrm{RH}, \mathrm{RMC}$ frequency was similar during the day and at night at all levels.

By site of recording, 15 individual patients with $\mathrm{RH}$ (56\%) had a diurnal RMC frequency elevated beyond the normal range at $+25 \mathrm{~cm}$ and $+15 \mathrm{~cm}$, and $20 \mathrm{RH}$ patients $(74 \%)$ had an increased RMC frequency at $+10 \mathrm{~cm}$. By comparison, the numbers of patients with NS who had an elevated diurnal RMC frequency were: $2(8 \%)$ at $+25 \mathrm{~cm}(\mathrm{p}=0.0007 v \mathrm{RH}), 0$ at $+15 \mathrm{~cm}(\mathrm{p}<0.0001 \vee \mathrm{RH})$, and $3(12 \%)$ at $+10 \mathrm{~cm}$ $(p<0.0001 v \mathrm{RH})$. Because of defecation (that is, catheter expulsion), it should be noted that of the six RH patients in whom the recording was terminated prematurely, four had increased RMC frequency during the day compared with none of those five patients with NS in whom no nocturnal data were acquired.

At night, the numbers of patients with $\mathrm{RH}$ who had an RMC frequency elevated above the normal range was 11 $(52 \%)$ at $+25 \mathrm{~cm}, 5(24 \%)$ at $+15 \mathrm{~cm}$, and $4(19 \%)$ at $+10 \mathrm{~cm}$. Only four patients with NS $(20 \%)$ at $+25 \mathrm{~cm}(p=0.05 v \mathrm{RH})$

Table 3 Results from the mixed model analysis of individual rectal motor complex parameters in control subjects (CS) and in those with rectal hypersensitivity (RH) and normal rectal sensation (NS)

\begin{tabular}{llcc}
\hline & \multicolumn{2}{l}{ Percentage change in geometric mean $(95 \% \mathrm{Cl})$} \\
\cline { 2 - 4 } Difference & AUC & Frequency & Duration \\
\hline CS-RH & $-11(-23$ to 4$)$ & $-14(-22 \text { to }-5)^{* *}$ & $14(10 \text { to } 18)^{* * *}$ \\
CS-NS & $-3(-30$ to 36$)$ & $-2(-22$ to 24$)$ & $13(9 \text { to } 18)^{* * *}$ \\
RH-NS & $9(-7$ to 28$)$ & $14(3 \text { to } 27)^{*}$ & $-0.4(-4$ to 3$)$ \\
Day $v$ night & $100(86 \text { to } 115)^{* * *}$ & $99(90 \text { to } 108)^{* * *}$ & $-11(-14 \text { to }-8)^{* * *}$ \\
\hline
\end{tabular}

No significant interaction effects between group and time were found.

$A U C$, area under the curve.

${ }^{*} \mathrm{p}<0.05 ;{ }^{* *} \mathrm{p}<0.01 ;{ }^{* * *} \mathrm{p}<0.001$

For analysis according to level of recording, please refer to the Gut website at hHtp://www.gutjnl.com/ supplemental. 
Table 4 Results from the mixed model analysis of individual rectal motor complex parameters in control subjects (CS) and in those with rectal hypersensitivity (RH) and normal rectal sensation (NS)

\begin{tabular}{lcc}
\hline & \multicolumn{2}{l}{ Percentage change in geometric mean $(95 \% \mathrm{Cl})$} \\
\cline { 2 - 3 } Difference & Amplitude & Periodicity \\
\hline Day (CS-RH) & $7(-1$ to 14$)$ & $93(76 \text { to } 111)^{* * *}$ \\
Day (CS-NS) & $-3(-14$ to 10$)$ & $15(3 \text { to } 29)^{*}$ \\
Day (RH-NS) & $-8(-15 \text { to }-1)^{*}$ & $-40(-46 \text { to }-35)^{* * *}$ \\
Night (CS - RH) & $-9(-15 \text { to }-2)^{*}$ & $40(28 \text { to } 53)^{* * *}$ \\
Night (CS-NS) & $-12(-22 \text { to }-1)^{*}$ & $9(-2$ to 21$)$ \\
Night (RH-NS) & $-4(-11$ to 4$)$ & $-22(-29 \text { to }-15)^{* * *}$ \\
CS (day v night) & $4(-3$ to 11$)$ & $23(10 \text { to } 37)^{* * *}$ \\
RH (day v night) & $-11(-15 \text { to }-7)^{* * *}$ & $-11(-17 \text { to }-5)^{* *}$ \\
NS (day v night) & $-7(-13$ to 0$)$ & $16(4 \text { to } 30)^{* * *}$ \\
\hline
\end{tabular}

Significant interaction effects between group and time was found. ${ }^{*} \mathrm{p}<0.05 ;{ }^{* *} \mathrm{p}<0.01 ;{ }^{* * *} \mathrm{p}<0.001$.

For analysis according to level of recording, please refer to the Gut website at http://www.gutjinl.com/supplemental.

but none at either $+15 \mathrm{~cm}(\mathrm{p}<0.05 v \mathrm{RH})$ or $+10 \mathrm{~cm}(\mathrm{p}=0.11$ $v \mathrm{RH}$ ) had an abnormally elevated RMC frequency.

\section{RMC variables}

Various differences existed between the study groups with regard to four of the five RMC variables-namely periodicity, duration, contraction, frequency, and median contraction amplitude. These results are summarised in tables 3 and 4 . For the principal study group (RH), RMC duration was significantly shorter than in controls (mean decrease in duration $13 \% \quad(95 \%$ CI $9-18 \%)$; $<<0.001)$, contraction frequency was higher than in CS (mean increase in frequency $14 \%(5-22 \%) ; \mathrm{p}<0.01)$ or NS (mean increase in frequency $14 \%(3-27 \%) ; \mathrm{p}<0.05)$, and median contraction amplitude was lower during the day than in patients with NS (mean decrease in amplitude 9\% $(1-15 \%) ; \mathrm{p}<0.05)$ but higher at night in comparison with controls (mean increase in amplitude $9 \%(2-15 \%)$; $\mathrm{p}<0.05)$. For RMC periodicity, results reflected those of RMC frequency (see above). For a full table of all data relating to RMC variables at the three recording levels for the three groups, please refer to the Gut website at http://www.gutjnl.com/supplemental.

Relationship between RMC variables and clinical history There was no correlation between RMC frequency and bowel frequency, rectal compliance, or rectal sensation.

\section{DISCUSSION}

The findings of this study contribute to our knowledge of the pathophysiology of UFI, providing new information regarding the relationship between rectal sensory and motor function and symptomatology in this condition. We have identified that in a subset of patients with UFI, namely those with RH (as defined by "simple" balloon distension), ${ }^{58}$ abnormalities of rectosigmoid motor physiology (reduced rectal compliance, increased high amplitude contractions, and altered cyclical contractile activity) exist that are not present in patients with UFI and normal rectal sensation. Such findings may underlie the clinical severity observed in the RH group, including more frequent sensations of urgency and increased bowel frequency, which is in agreement with a recent audit study of over 250 patients with this condition. ${ }^{5}$

\section{Psychological assessment}

It is well documented that increased stress can influence colonic motility, ${ }^{52}$ and thus an elevated state of anxiety could contribute to the increased reporting of urgency in patients with RH. However, in the current study, there were no differences in the proportions of patients with either RH or NS that suffered from anxiety or depression. RH has been considered to be a marker of IBS $^{58}$ but based on the Rome II criteria, ${ }^{44}$ none of the patients in the present study could be diagnosed as having IBS.

\section{Rectal sensation and anal sphincter function}

The definition of RH was based on data from healthy subjects whose ages were significantly younger than those of the study population. It has been shown that rectal sensory thresholds may increase with age, ${ }^{59}$ and therefore there is little risk that patients classified as $\mathrm{RH}$ were misclassified in the current study. However, if the control group were older, some patients with NS may have been reclassified as RH. Studies of HAC and RMC activity, stratified by age, are lacking but differences in ages between the control and patient groups may constitute a limitation of this study.

Nearly all patients with UFI were noted to have abnormal EAS function, irrespective of rectal sensory thresholds, supporting the observation that EAS dysfunction is the major pathophysiological factor in this condition..$^{5-7}$ In contrast, 50\% of patients with $\mathrm{RH}$ had evidence of IAS disruption, three times higher than in patients with NS. Although the proportions of patients with a functionally poor IAS (as reflected by reduced anal resting tone) were similar between groups, recording solely maximum resting tone does not reflect "global" IAS function. The presence of a weakened unstable IAS may lead to an increased number of internal sphincter relaxations ${ }^{60}$ and spontaneous anorectal sampling reflexes, ${ }^{61}$ so producing more frequent sensations of urgency. ${ }^{60}$ The IAS is a direct continuation of the circular muscle layer of the rectum and thereby provides a possible link between anal and rectal sensorimotor mechanisms. Such a hypothesis remains to be fully explored.

\section{Rectal sensation and compliance}

Although not in accordance with guidelines on standardised practice, ${ }^{62}$ we elected not to administer a rectal enema prior to assessment of compliance on the basis that such action may well disturb the "normal" physiological sensorimotor activity of the rectum, especially in the RH group; indeed, all patients at sigmoidoscopy had essentially empty rectums. As a group, patients with UFI and RH have reduced compliance compared with patients with UFI and NS, with $41 \%$ having compliance below the normal range. There was no correlation, however, between compliance and bowel frequency in RH.

That some patients with RH had normal compliance (and normal rectosigmoid contractile activity) suggests that, in a proportion, hypersensitivity may truly involve abnormalities of visceral afferent mechanisms. ${ }^{63}$ This is supported by the observation that RH patients exhibited enhanced perception of rectal and sigmoid motor events compared with NS and CS, and also from immunohistochemical studies which have suggested the possibility of sensitisation of peripheral mechanisms. ${ }^{6465}$

In addition to demonstrating reduced compliance in a proportion of patients with UFI, the finding of compliance greater than normal (that is, hypercompliance) in three patients from the NS group and one patient from the RH group may be a clue to the symptoms of rectal evacuatory difficulty concomitantly reported by some patients with UFI, ${ }^{466}$ and following continence restoring procedures. ${ }^{867}$

\section{Prolonged rectosigmoid manometry Methods}

Prolonged manometric recording of enteric phasic contractile activity is becoming an increasingly recognised clinical tool, especially in the evaluation of upper gastrointestinal 
function. ${ }^{37}{ }^{38}$ In this study, the absence of bowel preparation, and a fully ambulant subject, in whom extrinsic influences were minimised, meant that as close to normal physiological conditions were met. In addition, the use of semi- and fully automated quantitative methods of analysis has been shown to be superior in reliability and reproducibility than manual visual analysis of recordings. ${ }^{53}$ The computer algorithm overcomes not only problems of variable baseline and sudden changes in pressure due to body movements but also permits objectivity and eliminates observer bias. ${ }^{53}$ Furthermore, appropriate statistical methodology was employed, taking into account the non-independent and repeated nature of the recorded data. One limitation of prolonged manometry is possible catheter migration. However, maintenance of catheter position was confirmed radiologically in four subjects, and since results were similar at the three levels measured, this issue would not seem of great concern in respect of conclusions which may be drawn.

\section{Symptoms}

Not only was the frequency of urgency greater in patients with RH but there was a significantly stronger association between rectosigmoid motor events (notably HACs) and symptoms. This suggests that patients with $\mathrm{RH}$ may have enhanced perception of gut stimuli. Hypervigilance to intestinal motor events has also been reported in a proportion of patients with IBS, ${ }^{68}{ }^{69}$ in whom RH is a frequent finding. ${ }^{70}$

\section{Overall activity}

The results of this study suggest that the hindgut of patients with RH is hypercontractile compared with those with NS and healthy volunteers. Overall median contraction amplitude, maximum contraction amplitude, and AUC were significantly greater in RH compared with NS, with the frequency of HACs proportionally double in RH compared with NS. High amplitude propagated contractions (because of the short study segment used in the current recordings the term "propagation" was omitted from the description) are the motor correlate of mass intraluminal movement, ${ }^{19} 2654$ and the urge to defecate. ${ }^{22}{ }^{27}$ It is possible that exaggerated HAC activity may underlie symptomatology (for example, increased bowel frequency, secondary to more rapid colonic transit) in patients with UFI and RH, as has been suggested in patients with IBS. ${ }^{71}$ It must be stated however that in the present study, recording of pressure activity was confined to the rectosigmoid, and thus abnormal "colonic" motility or transit was not assessed. Assessment of "pancolonic" motor activity might provide more information as to whether the changes observed are confined to the distal hindgut or are more generalised.

A methodological concern regarding manometric recording is that recorded amplitudes are dependent on the luminal diameter of the viscus under study ${ }^{25}$; the above observations therefore may be artefactual in that a less compliant (as in the RH group) and/or narrower calibre rectum would give higher recorded values than a more compliant greater diameter rectum (or one which contains a significant volume of stool). ${ }^{72}$ Prolonged recordings of tonic and phasic activity using the barostat may be considered to overcome this limitation. $^{25}$

\section{RMC activity}

The most striking finding of this study was that RMC activity, notably frequency, was significantly higher in RH compared with NS and controls. Such observations should be independent of the methodological concerns described above. Fifty two per cent of patients with RH had a frequency of RMCs exceeding the upper limit of normal. ${ }^{23} 3031$ The function and origin of the RMC is still incompletely understood but it has been reported to be triggered by propagating pressure waves from the proximal colon. ${ }^{20}{ }^{32}$ It has been further suggested that RMC activity occurs in response to the arrival of stool or gas from the colon. Whether RMCs themselves truly propagate is the subject of debate. RMCs have been observed to move predominantly in a retrograde direction, with less than $5 \%$ propagating aborally. ${ }^{32}$ It is postulated that this would act as a "braking mechanism" to untimely flow of colonic contents ${ }^{32}$ and so keep the rectum empty. ${ }^{27}{ }^{31}$ The increased RMC activity seen in patients with RH may represent a form of protective mechanism to increased flow of colonic contents and/or merely reflect proximal colonic dysmotility. RMCs have also been suggested to be involved in the stimulus to defecate, ${ }^{30}$ and this may contribute to increased urgency in those RH patients who exhibited overall increased RMC frequency. If the RMC is indeed to be considered a marker of enteric neuromotor function, the abnormalities of various RMC variables demonstrated in this study, using appropriate statistical analyses, suggest a true intrinsic hindgut dysmotility, at least in a proportion of patients with UFI and RH.

In healthy subjects, rectal pressure is thought to increase during a RMC contraction..$^{73}$ This is invariably accompanied by a rise in anal sphincter tone so that anal canal pressure is always greater than rectal pressure, thus maintaining continence. ${ }^{73}$ In UFI patients with $\mathrm{RH}$, who have compromised anal sphincter function, the more frequent rises in rectal pressure which may occur as a result of increased RMC activity could afford some explanation as to the greater number of episodes of urgency experienced by these patients. $^{5}$

\section{Clinical implications}

The importance of this study is identification of a distinct pathophysiological subgroup of patients with UFI who exhibit exaggerated symptomatology, which may have important clinical implications for the management of UFI. It is becoming increasingly recognised that advances in the understanding of pathophysiology, rather than taxonomy based on symptoms alone, remain key to improved management. ${ }^{74}$ In patients with UFI and $\mathrm{RH}$, therapeutic options may include amitriptyline, which has previously been reported to reduce RMC frequency, ${ }^{24}$ sacral nerve stimulation, which has been shown to reduce urgency, ${ }^{75}$ and the recently described surgical technique of rectal "augmentation". ${ }^{8}$ By contrast, bowel retraining would seem to be less efficacious in the presence of $\mathrm{RH}^{.7}$

In conclusion, this study has attempted to evaluate the relations of rectal sensation and rectal motor activity in patients with UFI through comparison of three homogenous study groups. Only patients with RH have reduced compliance and rectosigmoid dysmotility, as well as enhanced perception of rectal and sigmoid motor events which may be peripherally ${ }^{64}$ or centrally mediated.$^{77}$ This sensory and motor disturbance appears to contribute to the symptomatology in such patients. Demonstration of extrasphincteric dysfunction in approximately $50 \%$ of all patients with UFI, in whom traditionally solely an anal pathology has been implicated and addressed, cannot be ignored. The association between $\mathrm{RH}$ and internal anal sphincter defects warrants further investigation. Finally, this study may have identified a clinical utility for prolonged rectosigmoid manometry in patients with UFI, in whom optimum management may involve more than simple repair of an anatomically disrupted anal sphincter. Further insight may be gained by evaluation of colonic function proximal to the rectosigmoid. Consideration to such comprehensive investigation should be given to patients presenting with UFI, in whom rectal hypersensitivity is demonstrable. 


\section{ACKNOWLEDGEMENT}

CLHC was supported by a Medical Research Council (UK) Clinical Training Fellowship.

\section{Authors' affiliations}

C L H Chan, P J Lunniss, N S Williams, S M Scott, Centre for Academic Surgery, Barts and the London, Queen Mary's School of Medicine and Dentistry, London, UK

D Wang, Medical Statistics Unit, London School of Hygiene and Tropical Medicine, London, UK

Conflict of interest: None declared.

This work was presented at the 19th International Symposium on Gastrointestinal Motility, Barcelona, Spain, 5-8 October 2003, and has been previously published in abstract form (Scott $M$ et al. Neurogastroenterol Motil 2003: 15:648)

\section{REFERENCES}

1 Nelson RL. Epidemiology of fecal incontinence. Gastroenterology 2004; 126:S3-7.

2 Leigh RJ, Turnberg LA. Faecal incontinence: the unvoiced symptom. Lancet 1982;1:1349-51.

3 Miner PB Jr. Economic and personal impact of fecal and urinary incontinence. Gastroenterology 2004;126:S8-13.

4 Rao SS. Pathophysiology of adult fecal incontinence. Gastroenterology 2004; 126:S14-22.

5 Chan CL, Scott SM, Williams NS, et al. Rectal hypersensitivity worsens stool frequency, urgency, and lifestyle in patients with urge fecal incontinence. Dis Colon Rectum 2005;48:134-40.

6 Engel AF, Kamm MA, Bartram Cl, et al. Relationship of symptoms in faecal incontinence to specific sphincter abnormalities. Int J Colorectal Dis 1995; 10:152-5.

7 Gee AS, Durdey P. Urge incontinence of faeces is a marker of severe external anal sphincter dysfunction. Br J Surg 1995;82:1179-82.

8 Williams NS, Ogunbiyi OA, Scott SM, et al. Rectal augmentation and stimulated gracilis anal neosphincter: a new approach in the management of fecal urgency and incontinence. Dis Colon Rectum 2001;44:192-8.

9 Wald A, Tunuguntla AK. Anorectal sensorimotor dysfunction in fecal incontinence and diabetes mellitus. Modification with biofeedback therapy. N Engl J Med 1984;310:1282-7.

10 Rasmussen O, Christensen B, Sorensen M, et al. Rectal compliance in the assessment of patients with fecal incontinence. Dis Colon Rectum 1990:33:650-3.

11 Siproudhis $L$, Bellissant $E$, Pagenault $M$, et al. Fecal incontinence with normal anal canal pressures: where is the piffall? Am J Gastroenterol 1999;94:1556-63.

12 Siproudhis L, Bellissant E, Juguet $F$, et al. Perception of and adaptation to rectal isobaric distension in patients with faecal incontinence. Gut 1999;44:687-92

13 Camilleri $M$. Testing the sensitivity hypothesis in practice: tools and methods, assumptions and piffalls. Gut 2002;51(suppl 1):i34-40.

14 Mertz H. Role of the brain and sensory pathways in gastrointestinal sensory disorders in humans. Gut 2002;51(suppl 1):i29-33.

15 Sun WM, Donnelly TC, Read NW. Utility of a combined test of anorectal manometry, electromyography, and sensation in determining the mechanism of 'idiopathic' faecal incontinence. Gut 1992;33:807-13.

16 Kellow JE, Delvaux M, Azpiroz F, et al. Principles of applied neurogastroenterology: physiology/motility-sensation. Gut 1999;45(suppl 2):1117-24

17 Felt-Bersma RJ, Sloots $C E$, Poen $A C$, et al. Rectal compliance as a routine measurement: extreme volumes have direct clinical impact and normal volumes exclude rectum as a problem. Dis Colon Rectum 2000;43:1732-8.

18 Krogh K, Mosdal C, Gregersen H, et al. Rectal wall properties in patients with acute and chronic spinal cord lesions. Dis Colon Rectum 2002;45:641-9.

19 Herbst F, Kamm MA, Morris GP, et al. Gastrointestinal transit and prolonged ambulatory colonic motility in health and faecal incontinence. Gut 1997;41:381-9.

20 Hagger R, Kumar D, Benson $M$, et al. Periodic colonic motor activity identified by 24 -h pancolonic ambulatory manometry in humans. Neurogastroenterol Motil 2002; 14:271-8.

21 Hagger R, Kumar D, Benson M, et al. Colonic motor activity in slow-transit idiopathic constipation as identified by 24 -h pancolonic ambulatory manometry. Neurogastroenterol Motil 2003;15:515-22.

22 Narducci F, Bassotti G, Gaburri M, et al. Twenty four hour manometric recording of colonic motor activity in healthy man. Gut 1987;28:17-25.

23 Rao SS, Sadeghi P, Beaty J, et al. Ambulatory 24-h colonic manometry in healthy humans. Am J Physiol Gastrointest Liver Physiol 2001;280:G629-39.

24 Santoro GA, Eitan BZ, Pryde A, et al. Open study of low-dose amitriptyline in the treatment of patients with idiopathic fecal incontinence. Dis Colon Rectum 2000;43:1676-81.

25 Scott SM. Manometric techniques for the evaluation of colonic motor activity: current status. Neurogastroenterol Motil 2003;15:483-513.

26 Torsoli A, Ramorino ML, Ammaturo MV, et al. Mass movements and intracolonic pressures. Am J Dig Dis 1971;16:693-6.
27 Crowell MD, Bassotti G, Cheskin $\amalg$, et al. Method for prolonged ambulatory monitoring of high-amplitude propagated contractions from colon. Am J Physiol 1991;261:G263-8.

28 Bampton PA, Dinning PG, Kennedy ML, et al. Spatial and temporal organization of pressure patterns throughout the unprepared colon during spontaneous defecation. Am J Gastroenterol 2000;95:1027-35.

29 Kamm MA, van DS Jr, Lennard-Jones JE. Colorectal and anal motility during defaecation. Lancet 1992;339:820.

30 Auwerda JJ, Bac DJ, Schouten WR. Circadian rhythm of rectal motor complexes. Dis Colon Rectum $2001 ; 44: 1328-32$.

31 Orkin BA, Hanson RB, Kelly KA. The rectal motor complex. J Gastrointest Motil 1989;1:5-8.

32 Rao SS, Welcher K. Periodic rectal motor activity: the intrinsic colonic gatekeeper? Am J Gastroenterol 1996;91:890-7.

33 Husebye E. The patterns of small bowel motility: physiology and implications in organic disease and functional disorders. Neurogastroenterol Motil 1999;11:141-61.

34 Kumar D, Williams NS, Waldron D, et al. Prolonged manometric recording of anorectal motor activity in ambulant human subjects: evidence of periodic activity. Gut 1989;30:1007-11.

35 Powell AK, Bywater RA. Murine intestinal migrating motor complexes: longitudinal components. Neurogastroenterol Motil 2003;15:245-56.

36 Spencer NJ. Control of migrating motor activity in the colon. Curr Opin Pharmacol 2001;1:604-10.

37 Camilleri M, Hasler WL, Parkman HP, et al. Measurement of gastrointestinal motility in the GI laboratory. Gastroenterology 1998;115:747-62.

38 Quigley EM, Deprez PH, Hellstrom P, et al. Ambulatory intestinal manometry: a consensus report on its clinical role. Dig Dis Sci 1997;42:2395-400.

39 Ferrara A, Pemberton JH, Grotz RL, et al. Prolonged ambulatory recording of anorectal motility in patients with slow-transit constipation. Am J Surg 1994;167:73-9.

40 Scott SM, Picon L, Knowles CH, et al. Automated quantitative analysis of nocturnal jejunal motor activity identifies abnormalities in individuals and subgroups of patients with slow transit constipation. Am J Gastroenterol 2003;98: $1123-34$

41 Spitzer RL, Williams JB, Gibbon $M$, et al. The structured clinical interview for DSM-III-R (SCID). I: History, rationale, and description, Arch Gen Psychiatry 1992;49:624-9.

42 Talley NJ, Phillips SF, Melton J III, et al. A patient questionnaire to identify bowel disease. Ann Intern Med 1989;111:671-4.

43 Snaith RP, Zigmond AS. The hospital anxiety and depression scale. $\mathrm{Br}$ Med J (Clin Res Ed) 1986;292:344.

44 Drossman DA. The functional gastrointestinal disorders and the Rome I process. Gut 1999;45(suppl 2):II1-5.

45 Read NW, Harford WV, Schmulen AC, et al. A clinical study of patients with fecal incontinence and diarrhea. Gastroenterology 1979;76:747-56.

46 Farthing MJ, Lennard-Jones JE. Sensibility of the rectum to distension and the anorectal distension reflex in ulcerative colitis. Gut 1978;19:64-9.

47 Kiff ES, Swash M. Normal proximal and delayed distal conduction in the pudendal nerves of patients with idiopathic (neurogenic) faecal incontinence. $J$ Neurol Neurosurg Psychiatry 1984;47:820-3.

48 Laurberg S, Swash M. Effects of aging on the anorectal sphincters and their innervation. Dis Colon Rectum 1989;32:737-42.

49 Eckardt VF, Jung B, Fischer B, et al. Anal endosonography in healthy subjects and patients with idiopathic fecal incontinence. Dis Colon Rectum 1994;37:235-42

50 Sloots CE, Felt-Bersma RJ, Cuesta MA, et al. Rectal visceral sensitivity in healthy volunteers: influences of gender, age and methods. Neurogastroenterol Motil 2000;12:361-8.

51 Hammer HF, Phillips SF, Camilleri M, et al. Rectal tone, distensibility, and perception: reproducibility and response to different distensions. Am J Physiol 1998;274:G584-90.

52 Rao SS, Hatfield RA, Suls JM, et al. Psychological and physical stress induce differential effects on human colonic motility. Am J Gastroentero 1998;93:985-90

53 Benson MJ, Castillo FD, Wingate DL, et al. The computer as referee in the analysis of human small bowel motility. Am J Physiol 1993;264:G645-54.

54 Bassotti G, Crowell MD, Whitehead WE. Contractile activity of the human colon: lessons from 24 hour studies. Gut 1993;34:129-33.

55 Goldstein H. Multilevel statistical models. London: Edward Arnold, 1995.

56 Donner A. A review of inference procedures for the intraclass correlation coefficient in the one-way random effects model. Int Stat Rev 1986;54:67-82.

57 Benson MJ, Castillo FD, Deeks JJ, et al. Assessment by prolonged ambulatory manometry of the effect of oral cisapride on proximal small bowel interdigestive motility. Dig Dis Sci 1992;37:1569-75.

58 Mertz H, Naliboff B, Munakata J, et al. Altered rectal perception is a biological marker of patients with irritable bowel syndrome. Gastroenterology 1995; 109:40-52.

59 Lagier E, Delvaux M, Vellas B, et al. Influence of age on rectal tone and sensitivity to distension in healthy subjects. Neurogastroenterol Motil 1999;11:101-7.

60 Sun WM, Read NW, Miner PB, et al. The role of transient internal sphincter relaxation in faecal incontinence? Int J Colorectal Dis 1990;5:31-6.

61 Miller R, Bartolo DC, Cervero F, et al. Anorectal sampling: a comparison of normal and incontinent patients. Br J Surg 1988;75:44-7.

62 Whitehead WE, Delvaux M. Standardization of barostat procedures for testing smooth muscle tone and sensory thresholds in the gastrointestinal tract. The Working Team of Glaxo-Wellcome Research, UK. Dig Dis Sci 1997;42:223-41 
63 Drewes AM, Petersen $P$, Rossel $P$, et al. Sensitivity and distensibility of the rectum and sigmoid colon in patients with irritable bowel syndrome. Scand J Gastroenterol 2001;36:827-32.

64 Chan CL, Facer P, Davis JB, et al. Sensory fibres expressing capsaicin receptor TRPV1 in patients with rectal hypersensitivity and faecal urgency. Lancet 2003:361:385-91.

65 McMahon SB. Sensitisation of gastrointestinal tract afferents. Gut 2004;53(suppl 2):ii13-15.

66 Cheung O, Wald A. Review article: the management of pelvic floor disorders. Aliment Pharmacol Ther 2004:19:481-95.

67 Malouf AJ, Norton CS, Engel AF, et al. Long-term results of overlapping anterior anal-sphincter repair for obstetric trauma. Lancet 2000;355:260-5.

68 Kellow JE, Eckersley CM, Jones MP. Enhanced perception of physiological intestinal motility in the irritable bowel syndrome. Gastroenterology 1991;101:1621-7.

69 Naliboff BD, Munakata J, Fullerton S, et al. Evidence for two distinct perceptual alterations in irritable bowel syndrome. Gut 1997:41:505-12.
70 Lembo T Munakata J Naliboff $B$ et al Sigmoid afferent mechanisms in patients with irritable bowel syndrome. Dig Dis Sci 1997;42:1112-20.

71 Rogers J, Henry MM, Misiewicz JJ. Increased segmental activity and intraluminal pressures in the sigmoid colon of patients with the irritable bowel syndrome. Gut 1989;30:634-41.

72 Kumar D, Gustavsson S, Wingate D. An illustrated guide to gastrointestinal motility. Edinburgh: Churchill Livingstone, 1993.

73 Ferrara A, Pemberton JH, Levin KE, et al. Relationship between anal canal tone and rectal motor activity. Dis Colon Rectum 1993:36:337-42.

74 Camilleri M, Talley NJ. Pathophysiology as a basis for understanding symptom complexes and therapeutic targets. Neurogastroenterol Motil 2004;16:135-42.

75 Kenefick NJ, Vaizey CJ, Cohen RC, et al. Medium-term results of permanent sacral nerve stimulation for faecal incontinence. Br J Surg 2002;89:896-901.

76 Glia A, Gylin M, Akerlund JE, et al. Biofeedback training in patients with fecal incontinence. Dis Colon Rectum 1998:41:359-64.

77 Whitehead WE, Palsson OS. Is rectal pain sensitivity a biological marker for irritable bowel syndrome: psychological influences on pain perception. Gastroenterology 1998;115:1263-71.

\section{EDITOR'S QUIZ: GI SNAPSHOTS}

\section{An unusual case of hepatosplenomegaly}

\section{Clinical presentation}

A 21 year old Asian female presented to our clinic with impaired renal function (creatinine level $217 \mu \mathrm{mol} / \mathrm{l}$ ). There was no history of note. Physical examination elicited hepatosplenomegaly. There were no other positive findings. Urine analysis was unremarkable. Laboratory investigations demonstrated a microcytic anaemia, with depressed total white cell and platelet counts, consistent with hypersplenism. Normal synthetic liver function was noted. Alkaline phosphatase levels were raised (401 iu/l).

Past medical notes (initially not available) described hepatosplenomegaly since birth, first noted in Pakistan. Liver biopsy performed in the UK at the age of two years demonstrated increased collagen deposition around the bile ducts. The patient had been lost to follow up.

Abdominal ultrasound demonstrated normal sized kidneys with hepatosplenomegaly (normal liver echotexture) and a dilated extrahepatic common bile duct $(1.1 \mathrm{~cm})$. The gall bladder appeared normal with no calculi. Computed tomography of the abdomen confirmed these findings.

A magnetic resonance cholangiopancreatography scan was performed fig 1 .

\section{Question}

What do these scans show and what is the unifying diagnosis?

See page 1331 for answer

This case is submitted by:

D Joshi, J Dunga, A James, M M Yaqoob Department of Renal Medicine and Transplantation, Barts and The London NHS Trust, London, UK
Robin Spiller, Editor
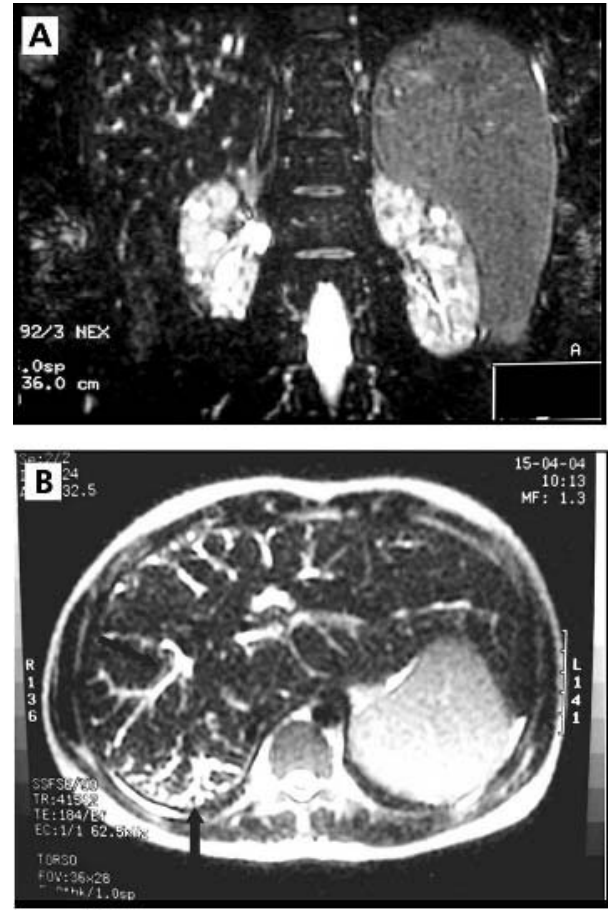

Figure 1 Magnetic resonance cholangiopancreatography scan of the abdomen (A) and intrahepatic biliary ducts (B)

Correspondence to: $\operatorname{Dr}$ M M Yaqoob, Department of Renal Medicine and Transplantation, Barts and The London NHS Trust, Whitechapel, London E1 1BB, UK; m.m.yaqoob@qmul.ac.uk doi: $10.1136 /$ gut.2005.064824 